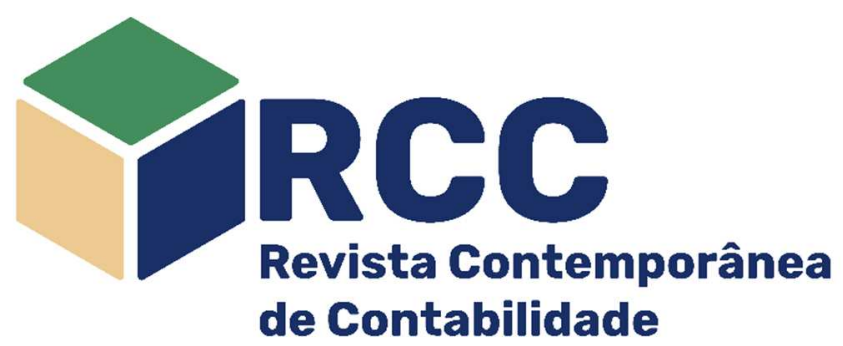

\title{
Estrutura de capital e financial distress em empresas familiares e não familiares brasileiras
}

\author{
Capital Structure and financial distress in family and non-family Brazilian companies
}

\section{Estructura de capital y financial distress en empresas familiares y no familiares brasileñas}

\author{
Edgar Pamplona* \\ Doutorando em Ciências Contábeis e Administração no \\ Programa de Pós-Graduação em \\ Ciências Contábeis - PPGCC (FURB), Blumenau/SC, Brasil \\ edgarpamplona@hotmail.com \\ https://orcid.org/0000-0002-2579-5458 (1)
}

\author{
Alice Carolina Ames \\ Doutoranda em Ciências Contábeis e Administração no \\ Programa de Pós-Graduação em \\ Ciências Contábeis - PPGCC (FURB), Blumenau/SC, Brasil \\ aliceames@hotmail.com \\ https://orcid.org/0000-0002-8287-8831 [D \\ Tarcísio Pedro da Silva \\ Doutor em Ciências Contábeis e Administração pelo \\ Programa de Pós-Graduação em Ciências Contábeis - PPGCC (FURB) \\ Professor do Programa de Pós-Graduação em \\ Ciências Contábeis - PPGCC (FURB), Blumenau/SC, Brasil \\ tarcisio@furb.br \\ https://orcid.org/0000-0002-2370-791X
}

Endereço do contato principal para correspondência* Rua Antônio da Veiga, 140 - Sala D202 - Bairro Itoupava Seca, CEP: 89.030-903, Blumenau/SC, Brasil

\begin{abstract}
Resumo
Este estudo tem por objetivo verificar a influência da estrutura de capital no financial distress em empresas familiares e não familiares brasileiras. Realizou-se pesquisa descritiva, documental e quantitativa. A amostra abrangeu 137 empresas, sendo 65 familiares e 72 não familiares, analisadas de 2011 a 2017. Observou-se, por meio de três medidas - endividamento total, de longo prazo e oneroso -, que a estrutura de capital influencia na probabilidade de financial distress tanto de empresas familiares como de organizações não familiares. Mais importante, tem-se que estas medidas divergem de sinal tanto entre elas como em função da gestão e propriedade corporativa (se familiar ou não familiar). Assim, a contribuição deste estudo perpassa pelo reconhecimento de que gestores, investidores e outras partes interessadas devem observar as medidas de estrutura de capital de forma distinta para reconhecerem o evento de financial distress e, em função disto, tomarem decisões assertivas diante de seus interesses subjacentes.
\end{abstract}

Palavras-chave: Estrutura de capital; Financial distress; Empresas familiares; Empresas não familiares

\begin{abstract}
The aim of the study was to verify the influence of capital structure on financial distress in family and nonfamily brazilian companies. We conducted a descriptive, documentary and quantitative research. The sample included 137 companies, of which 65 were family members and 72 were non-family, analyzed from 2011 to 2017. It was observed that, through three measures - total debt, long-term debt and costly debt - the capital structure influences the probability of financial distress of both family and non-family companies. More importantly, these measures diverge from each other and according as from management and corporate ownership (if family or non-family companies). Thus, the contribution of this study stems from the recognition that managers, investors and other interested parties should observe capital structure measures in a different way to recognize the event of financial distress and, as a result, make assertive decisions regarding their underlying interests.
\end{abstract}

Keywords: Capital structure; Financial distress; Family companies; Non-family companies 


\section{Resumen}

Este estudio tiene por objetivo verificar la influencia de la estructura de capital en el financial distress en empresas familiares y no familiares brasileñas. Se realizó una investigación descriptiva, documental y cuantitativa. La muestra abarcó 137 empresas, siendo 65 familiares y 72 no familiares, analizadas de 2011 a 2017. Se observó, por medio de tres medidas - endeudamiento total, a largo plazo y oneroso -, que la estructura de capital influye en la probabilidad de financial distress tanto de empresas familiares como de organizaciones no familiares. Más importante, se tiene que estas medidas difieren de señal tanto entre ellas como en función de la gestión y propiedad corporativa (si es familiar o no familiar). Así, la contribución de este estudio atraviesa el reconocimiento de que gestores, inversores y otras partes interesadas deben observar las medidas de estructura de capital de forma distinta para reconocer el evento de financial distress y, en función de ello, tomar decisiones asertivas ante sus intereses subyacentes.

Palabras clave: Estructura de capital; Financial distress; Empresas familiares; Empresas no familiares

\section{Introdução}

A partir da discussão em relação às crises financeiras que assolam todo o mundo e a competitividade acirrada entre os mercados, observa-se as empresas cada vez mais vulneráveis a falência, sendo isto motivo de preocupação no âmbito corporativo. Pesquisadores e responsáveis por políticas têm enfatizado a necessidade de reformas, buscando soluções mais ágeis, claras e econômicas a fim de minimizar turbulências financeiras para as organizações, sendo estas também conhecidas por financial distress. Busca-se promover um ambiente sinérgico para práticas saudáveis em relação as dívidas corporativas, fatores de confiança e taxa de sobrevivência mais alta para as empresas (NIGAM; BOUGHANMI, 2017).

O financial distress é visto de maneira custosa, pois impulsiona as empresas a tomarem decisões que podem afetar seus detentores de capital e/ou partes interessadas, induzindo, ainda, os concorrentes de maneira a aproveitar a situação para aumentar a participação no mercado, o que maximiza, por consequência, o sofrimento da organização angustiada financeiramente (OPLER; TITMAN, 1994). Com efeito, financial distress pode ser visto, portanto, como um estágio de declínio corporativo que tende a anteceder eventos relacionados à falência ou a liquidação corporativa (PLATT; PLATT, 2002).

Como resposta ao financial distress, as empresas tendem a optar pela reestruturação de seus ativos e passivos, em que ações como a venda de bens, união com outras sociedades, diminuição nas despesas, reestruturação de dívidas, entre outras decisões são necessárias (ASQUITH; GERTNER; SCHARFSTEIN, 1994). A este respeito, destaca-se que a reestruturação financeira é vista como uma maneira de reformular a estrutura de capital de uma organização a fim de diminuir a aflição perante juros e reembolsos da dívida, sendo a emissão de ações uma alternativa usualmente importante para empresas que enfrentam o financial distress (SUDARSANAM; LAI, 2001).

Em referência a tal fenômeno, é perceptível que a estrutura de capital é um potencial fator relevante em relação ao financial distress das organizações. Salehi, Lofti e Farhangdoust (2017) relatam que as dificuldades financeiras incluem custos de agenciamento da dívida e custos de falência. Para Ataünal e Aybars (2017), quando a probabilidade de dificuldades financeiras é baixa, as organizações tendem a preferir aumento da alavancagem para usufruir das vantagens fiscais da dívida. Em contrapartida, por vezes, observase que empresas lucrativas operam, ao longo do tempo, com baixos índices de endividamento (ATAÜNAL; AYBARS, 2017). Tais perspectivas remetem as principais teorias de estrutura de capital, sendo a trade-off e a pecking-order.

Logo, com conhecimento que a estrutura de capital pode impactar o desempenho corporativo e o valor de mercado da empresa e, ainda, tendo-se as teorias trade-off e pecking-order a fim de compreender a forma como as organizações captam recursos, espera-se que a estrutura de capital tenha potencial de determinar o financial distress corporativo. Empiricamente, no contexto norte-americano, Opler e Titman (1994) verificaram que indústrias em financial distress possuíam predominantemente alta alavancagem (OPLER; TITMAN, 1994), tendendo, portanto, as empresas que preferem o financiamento interno, consonante com a pecking-order theory, serem mais estáveis financeiramente.

O clássico estudo de Opler e Titman (1994) impulsionou o desenvolvimento, em maior escala, de pesquisas acerca do tema, que permanecem foco até a contemporaneidade. Neste cenário, destaque pode ser dado a estudos internacionais recentes como de Kisman e Krisandi (2019) na Indonésia, Lucky e Michael (2019) na Nigéria e Abdioğlu (2019) na Turquia, em que se nota, adicionalmente, a extensão de pesquisas deste tipo também a nações em desenvolvimento. No Brasil, o tema específico e seus similares ganhou notoriedade apenas nos últimos anos, com destaque para Bezerra, Lagioia e Pereira (2019) e Lunardi, Bilk e Rodrigues Junior (2020).

Outro aspecto que pode interferir no fenômeno observado é a propriedade e a gestão da organização. Empresas familiares apresentam maior aversão ao risco (ANDERSON; DURU; REEB, 2012), o que deve impactar no nível de alavancagem da empresa. Precisamente, organizações do tipo familiar tendem a preferir proporção inferior de capital de terceiros comparativamente a empresas não familiares, visando estarem menos propensas ao risco de embaraço financeiro. Logo, torna-se primordial entender de forma separada como a estrutura de capital influencia no financial distress de empresas familiares e não familiares. 
No ramo descrito, encontra-se subnotificação de evidências acerca do tema, tanto no cenário internacional quanto no nacional. Pesquisas internacionais que abordam financial distress, estrutura de capital e influência familiar de forma concomitante são raras, enquanto no cenário nacional não foi observado qualquer evidência. A efeito, internacionalmente, Gottardo e Moisello (2019), com amostra de empresas italianas, identificaram que a estrutura de capital tem significado diferente para empresas familiares e não familiares a fim de interferir na probabilidade das organizações em entrar em dificuldades financeiras.

Portanto, diante das conjunturas observadas e da lacuna de pesquisa existente no cenário brasileiro, representante de países em desenvolvimento, esta pesquisa visa trazer novos insights a fim de contribuir para com o conhecimento acerca do tema, ao contemplar a seguinte questão-problema de pesquisa: qual a influência da estrutura de capital no financial distress em empresas familiares e não familiares brasileiras? Por conseguinte, o objetivo de estudo é verificar a influência da estrutura de capital no financial distress em empresas familiares e não familiares brasileiras.

O estudo justifica-se pela importância do tema para inúmeros usuários da informação. Pesquisas deste tipo podem fornecer aviso para que empresas possam tomar medidas corretivas contra as dificuldades financeiras, seja de forma antecipada (GENG; BOSE; CHEN, 2015) ou a posteriori. Além de auxiliar gestores, pode ainda ser importante para investidores atuais e potenciais para a tomada de decisão de retenção ou compra de ações das empresas. Portanto, os benefícios produzidos a gestores, investidores e outros stakeholders da informação, elucidam a atenção despendida atualmente por pesquisadores de todo o mundo acerca do tema proposto.

Além disso, apesar da crescente comparabilidade entre empresas familiares e não familiares na literatura como um todo, número reduzido de pesquisas tem buscado entender as diferenciações destas no cerne específico do tema proposto. Para Anderson, Duru e Reeb (2012), as empresas familiares tendem a comprometer parcela inferior com investimentos arriscados, sendo mais cautelosas e conservadoras em suas decisões de investimentos (ANDERSON; DURU; REEB, 2012). Desta forma, é de se esperar que tais empresas encontrem proporcionalmente menos dificuldades financeiras, visto sua constância no mercado, em que busca a sobrevivência há longo prazo. Empiricamente, Gottardo e Moisello (2019) observaram efeito complacente ao refiro em teoria no contexto desenvolvido italiano.

Ao que pese o cenário em estudo, o Brasil, por ser um país em desenvolvimento, tende a sofrer maiores oscilações econômicas, o que intensifica a complexidade do fenômeno, especialmente com foco comparativo de empresas familiares e não familiares, podendo proporcionar novos insights para o avanço da literatura. Tais novos insights partem primordialmente de dois elementos principais, sendo: 1) não se observou, na literatura nacional, pesquisas que contemplem simultaneamente financial distress, estrutura de capital e empresas familiares e não familiares; e, 2) não se observou, na literatura internacional, pesquisas que contemplem os três elementos descritos e que abrangem as múltiplas medidas de estrutura de capital aqui testadas - endividamento total, endividamento de longo prazo e endividamento oneroso. Portanto, 0 presente estudo tem potencial de proporcionar novos elementos a literatura nacional e a enrobustecer as evidências observadas internacionalmente.

\section{Referencial Teórico}

\subsection{Financial Distress}

Em finanças corporativas, o estudo acerca da previsibilidade de dificuldades financeiras das corporações tem sido considerado dos mais importantes. Horta, Alves e Carvalho (2014) e Sabela et al. (2018) mencionam que governo, acionistas, financiadores externos, agências de classificação de crédito, auditores, fornecedores, clientes e funcionários são stakeholders afetados por cenários de dificuldades financeiras das empresas e são, portanto, interessados em identificar "problemas de insolvência" em andamento. De fato, a detecção antecipada de financial distress é essencial para a proteção de um número abrangente de interessados. Logo, a predição e classificação corporativa a fim de determiná-las como potenciais candidatas a dificuldades financeiras se tornou tema central de debate e pesquisa.

Empiricamente, os estudos acerca dos indicadores financeiros que apresentam potencial de prever o fracasso corporativo ganharam destaque na literatura após meados da década de 1960. A pesquisa de Beaver (1966), que verificou relações financeiras como preditoras do fracasso corporativo e o estudo de Altman (1968), que fez uso, por meio de análise discriminante, de índices financeiros para identificar antecipadamente falências corporativas, são consideradas marcos seminais empíricos na temática. Desde então, conforme Sabela et al. (2018), a literatura tem demonstrado um claro desenvolvimento de modelos financeiros e de técnicas estatísticas para prever dificuldades financeiras corporativas.

Neste sentido, dois aspectos essenciais são: 1) o motivo que levam as empresas a entrarem em dificuldades financeiras; e, 2) como este aspecto é identificado, visto sua complexidade. Em referência ao primeiro, Whitaker (1999) menciona que majoritariamente empresas entram em dificuldades financeiras como fruto de má administração e não por dificuldades econômicas generalizadas do setor ou do país em que operam. Além disso, ações acertadas da gestão são um determinante significativo de recuperação e melhoria no valor de mercado das empresas, inclusive para aquelas que foram, historicamente, mal administradas. 
O reflexo da má administração faz com que empresas angustiadas financeiramente emitam sinais, que conforme Rechden e Miller (2015) podem perpassar por violações contratuais, dificuldades de fluxo de caixa, falha na relação com fornecedores, emissão de relatórios inadequados e/ou com atraso, negligência na gestão de pessoal que tenderá a alta rotatividade, flutuações significativas nas avaliações de ativos, indícios de fraude e/ou corrupção, governança corporativa ineficiente, entre outros (RECHDEN; MILLER, 2015), afetando o bom funcionamento corporativo.

Todavia, apesar dos inúmeros indícios existentes e adentrando ao segundo fator, classificar uma empresa como em dificuldade financeira tem sido um dos grandes desafios de pesquisadores. Platt e Platt (2002) e Kisman e Krisandi (2019) mencionam que a dificuldade financeira pode ser compreendida como um estágio de declínio corporativo que pode vir a preceder eventos mais catastróficos, como a falência ou a liquidação (PLATT; PLATT, 2002; KISMAN; KRISANDI, 2019). A contrariedade em questão é determinar em que momento as empresas entram em dificuldade financeira, pois diferentemente da falência ou liquidação, esta não possui uma data concreta, o que amplia a discussão entre pesquisadores da área. Pindado, Rodrigues e Torre (2008) mencionam que o sofrimento financeiro corporativo independe de suas consequências legais, corroborando, assim, com a complexidade de observância do fenômeno em questão.

Em estudos acerca do tema, tem-se observado diferentes formas de classificar uma empresa como em dificuldade financeira. Wruck (1990) menciona que uma empresa pode ser definida como insolvente quando apresenta patrimônio líquido negativo. Já Pindado, Rodrigues e Torre (2008) defendem que se pode estabelecer como uma empresa financeiramente angustiada aquela que: 1) apresentar EBITDA - Earnings Before Interest, Taxes, Depreciation and Amortization - inferior à despesa financeira no período de dois anos consecutivos; ou, 2) queda no valor de mercado em igual lacuna temporal. O primeiro critério está pautado que as empresas não conseguem gerar recursos suficientes por meio de suas atividades operacionais para cumprir com as obrigações financeiras e, pelo segundo critério, de que o déficit dos fundos operacionais mencionados seja negativamente avaliado pelo mercado, acarretando em sequenciais diminuições de valor da empresa. Tais classificações são amplamente utilizadas na literatura, com aplicações inclusive no cenário brasileiro, a efeito de Rezende et al. (2017).

Especificamente acerca da medida descrita do EBITDA pelas despesas financeiras, esta parte de uma lógica de regime de competência, sendo, portanto, uma aproximação da realidade financeira. De acordo com Dumont e Schmit (2014), o lucro, sendo o EBITDA uma das representações, pode estar sujeito a pagamentos diferidos, significando que este pode ocorrer mesmo com o fluxo de caixa negativo. Para mitigar tal problema, Small, Smidt e Joseph (2016) sugerem a utilização da demonstração do fluxo de caixa. Um fluxo de caixa operacional negativo indica que a organização está despendendo mais caixa do que gerando em suas operações, tornando-se um indicador essencial na previsão de dificuldades financeiras.

Em geral, observa-se que identificar o momento em que uma organização se encontra em dificuldade financeira é complexo, visto o desenvolvimento de inúmeros parâmetros para tanto. De qualquer forma, independentemente do critério adotado para dimensionar o fenômeno, acredita-se que a estrutura de capital tenha potencial de explicar a condição financeira de uma organização, conforme discussão apresentada na próxima seção.

\subsection{Estrutura de Capital}

Ao se considerarem os atritos de mercado, pesquisadores desenvolveram teorias para fornecer explicações racionais em relação aos ajustes do nível de endividamento das organizações (HANG et al., 2017). No final da década de 1950 e início da década de 1960, os estudos de Modigliani e Miller (1958; 1963) foram considerados referências ao buscar a compreensão de como as organizações devem se financiar para que possam maximizar o seu valor. Salienta-se a consideração dos impostos nas decisões de estrutura de capital, na perspectiva de que as organizações devem se estruturar com proporções altas de dívidas, ou seja, preferir o uso de capital de terceiros, observando que esse nível mais elevado possibilita vantagens fiscais advindas dos juros.

A trade-off theory de estrutura de capital advém do entendimento seminal mencionado e, atrelada a desenvolvimentos posteriores, foi consolidada mediante a compreensão de que existe um nível de endividamento ótimo para as empresas, sendo este determinado por custos e benefícios de empréstimos, ou seja, há um balanceamento entre os benefícios ficais dos juros e os custos de falência ou complicação financeira (MYERS, 1984). Outra teoria de estrutura de capital, a pecking-order theory, também foi consolidada na década de 1980, sendo adicionada a teoria trade-off como as duas principais voltadas a estrutura de capital corporativa.

Precisamente, para Myers (1984), pela teoria do pecking-order, as empresas optam primeiramente por financiamento interno, adaptando os índices de pagamento de dividendos conforme as oportunidades de investimento e, quando esta fonte de financiamento se esgota, as organizações captam, sequencialmente, recursos por dívidas, pelos títulos híbridos e, finalmente, não havendo mais alternativas, emitem ações (capital) no mercado. Logo, observa-se que para fins de diminuição dos custos de financiamento, deve-se preferir a fonte que apresenta menor assimetria informacional. 
De maneira consolidada, conforme Frank e Goyal (2009), o que pode ser constatado na pecking-order diferentemente a trade-off, é que não há um índice de endividamento ótimo, visto que a teoria é observada em termos de assimetria da informação, ainda que ambas as teorias partem de imperfeições no mercado. Lucky e Michael (2019) mencionam que os mercados são imperfeitos devido a fatores como impostos, custos de falência, assimetria de informações, entre outros, o que adentra ao âmago tanto da trade-off theory como da pecking-order theory.

Ao abordar a estrutura de capital com o financial distress, tem-se a reestruturação financeira como a reformulação da estrutura de capital de uma organização, com o intuito de minimizar o impacto dos juros e do pagamento de dívidas (SUDARSANAM; LAI, 2001). Empiricamente, vários pesquisadores tem procurado compreender o fenômeno de estrutura de capital e financial distress. Kahl (2002) descreveu o financial distress como um processo dinâmico, afirmando que há incentivos para que os credores saibam lidar sobre as perspectivas de recuperação da organização. De fato, para Bezerra, Lagioia e Pereira (2019), as indicações de insolvência das empresas devem ser utilizadas pelos credores, de modo a mitigar o risco de crédito quando houver a concessão.

Abdioğlu (2019) investigou a relação entre dificuldades financeiras e decisões de estrutura de capital. A amostra de pesquisa foi composta por organizações turcas, com dados de 2007 a 2017. As constatações sugerem que a dificuldade financeira corporativa aumenta à medida que o endividamento se eleva. Todavia, é essencial mencionar que inserindo o aspecto de maturidade do endividamento, observou-se que a dívida de curto prazo traz maiores probabilidades de dificuldade financeira ou, em análise de ângulo invertido, a dívida de longo prazo é benéfica para a saúde financeira corporativa.

Além da complexidade já existente entre estrutura de capital e financial distress, um elemento que pode ser inserido neste fenômeno e que o torna ainda mais abrangente é a diferenciação entre empresas familiares e não familiares. Neste sentido, a discussão deste elemento no cerne do fenômeno em questão é realizada na próxima seção.

\subsection{Empresas Familiares}

A importância das empresas familiares pode ser observada na literatura por meio do crescente interesse de estudos neste tipo de organização (SHARMA, 2004), dado que as famílias são uma classe singular de investidores (ANDERSON; MANSI; REEB, 2003), requerendo seu entendimento em separado. Para Oro, Beuren e Hein (2009), ao se abordar empresas familiares, o capital, a família e a empresa são dimensões a serem consideradas. Quanto a caracterização, dois aspectos devem ser destacados em empresas familiares: a participação majoritária da família no capital da organização e a participação de membros pertencentes à família na gestão dos negócios (ORO; BEUREN; HEIN, 2009), o que torna este tipo de empresa única.

Na literatura teórica e em estudos empíricos, observa-se a existência de uma variedade de conceitos, os quais buscam a compreensão do que efetivamente caracteriza uma organização como familiar. Geralmente, as conceituações permeiam pelo controle acionário e o envolvimento da família na gestão dos negócios, em que, se a família estiver contemplada em alguma dessas dimensões, a empresa analisada apresenta caráter familiar (OLIVEIRA; ALBUQUERQUE; PEREIRA, 2012). Assim, dentre as classificações para empresas familiares, têm-se os seguintes critérios como usuais: membros da família (dois ou mais) participam da gestão (ANDERSON; REEB, 2003; LAFFRANCHINI; BRAUN, 2014); e/ou, membros da família possuem 10\% ou mais das ações da organização (MOK; LAM; CHEUNG, 1992; LAFFRANCHINI; BRAUN, 2014).

Neste cenário, um dos aspectos essenciais a serem debatidos é como a gestão e à propriedade familiar impactam nas escolhas de estrutura de capital corporativa. O estudo de Schmid (2013) analisou os motivos que levam os fundadores e suas famílias a influenciarem nas decisões de estrutura de capital das organizações na Alemanha. Os resultados apontam que estes utilizam a estrutura de capital a fim de otimizar o controle sobre as organizações, em que o intuito de manter o poder é o principal motivo dos acionistas controladores mais importantes, sendo estes geralmente os fundadores e suas famílias.

Santos, Moreira e Vieira (2014) analisaram a distribuição de poder entre vários blockholders de uma organização como determinante da alavancagem das empresas na Europa Ocidental. Dentre os resultados, observou-se relação negativa entre o principal blockholder (nitidamente familiar) e a alavancagem da organização. Logo, a tipicidade de propriedade familiar corporativa afeta negativamente a alavancagem das organizações, confirmando a teoria de que essas são avessas a um aumento na dívida devido ao risco de falência e financial distress. Não há toa, Pamplona et al. (2019) defendem que há diferenças entre empresas familiares e não familiares, sobretudo quanto ao nível de manutenção de reservas de recursos financeiros, recursos estes que operam como proteção ao financial distress. Precisamente, as constatações no cenário brasileiro são de que as empresas familiares tendem a reter, como garantias, mais recursos financeiros do que suas contrapartes não familiares.

Kayo, Brunaldi e Aldrighi (2018) examinaram as diferenças entre os índices de alavancagem e ajuste na estrutura de capital de empresas familiares e não familiares brasileiras. Observou-se que ao contrário do argumento convencional de que empresas familiares têm níveis mais baixos de endividamento por aversão 
ao financial distress, nas empresas familiares brasileiras a alavancagem é maior do que para as empresas não familiares. Além disso, as empresas familiares ainda apresentaram velocidade de ajuste menor de sua estrutura de capital em comparação as empresas não familiares, apoiando a sentença de que os gestores das corporações familiares são mais confiantes e otimistas em relação aos gestores das empresas não familiares.

Gottardo e Moisello (2019) estudaram o efeito da alavancagem na probabilidade de uma empresa sofrer problemas financeiros levando em consideração a influência da família nos negócios. A abordagem de tal fenômeno contemplou empresas italianas familiares e não familiares no período de 2004 a 2013 . Os resultados apontam que as empresas familiares tem menor probabilidade de sofrer problemas financeiros. Além disso, em geral, as variáveis estudadas, que incluem de estrutura de capital, apresentam um significado diferente na probabilidade de dificuldades financeiras das empresas familiares e não familiares.

Com base no conjunto de pesquisas expostas, é perceptível a complexidade existente na estruturação do capital de uma empresa familiar, visto que na literatura encontram-se defensores, em maior escala, de que este tipo de organização é avessa ao risco e, portanto, buscará o financiamento prioritário por recursos próprios (alavancagem mais baixa), enquanto por outro há defensores do entendimento de que gestores familiares são empreendedores natos e, portanto, possuem maior confiança e otimismo em suas decisões, 0 que resultará em maior grau de alavancagem nas empresas que administram.

Tal característica pode impactar na probabilidade de entrar em financial distress das empresas, visto que a estrutura de capital, se mal dimensionada, tende a aumentar de forma excessiva os custos de falência/embaraço financeiro. Por mais que não se possa afirmar o sinal da relação, mediante conceitos e evidências controversas na literatura prévia, já é consolidado que a estrutura de capital tem potencial de afetar a probabilidade de financial distress corporativo, sendo que a forma de controle e gestão da empresa em análise é um aspecto que interfere em tal relação. Portanto, a hipótese desta pesquisa fica assim dimensionada:

$H_{1}$ : Existe relação entre a estrutura de capital e o financial distress em empresas brasileiras, sendo esta diferente para empresas familiares comparativamente a suas contrapartes não familiares.

\section{Procedimentos Metodológicos}

Com o intuito de verificar a influência da estrutura de capital no financial distress em empresas familiares e não familiares brasileiras, a presente pesquisa é delineada quanto aos objetivos como descritiva, uma vez que observa variáveis sem manipulá-las. Ademais, configura-se como de análise documental, visto que os dados utilizados para cálculo das variáveis foram obtidos por meio da base de dados Economática ${ }^{\circledR}$, de informações constantes no website da Brasil, Bolsa, Balcão (B3) e do website do Banco Mundial (World Bank). Por fim, a abordagem do problema é definida como quantitativa, pois identifica a influência das variáveis com o uso de técnicas estatísticas.

A população da pesquisa foi composta por todas as empresas industriais brasileiras de capital aberto listadas na Brasil, Bolsa, Balcão (B3). Para composição da amostra de pesquisa, inicialmente foram excluídas as corporações cujos dados financeiros foram considerados outliers por estarem mais de dois desvios-padrão distantes da média geral, delineamento este usual, como pode ser observado em Pamplona et al. (2019). Tal procedimento é fundamental para se produzir resultados consistentes, sem enviesamentos derivados de informações extremas e incomuns. Ademais, retirou-se da amostra as organizações que não apresentavam dados para operacionalização das variáveis de pesquisa em todos os períodos estudados. Por fim, foram ainda excluídas as empresas cujo patrimônio líquido é negativo (passivo a descoberto), visto que nestes casos específicos, as organizações deixam a condição de escolher sua estrutura de capital, objetivando apenas sobreviver ao mercado competitivo.

Com base no exposto, ao todo, a amostra de pesquisa foi composta por 137 empresas que geraram ao todo 959 observações entre os anos de 2011 e 2017. A lacuna temporal de análise, que abrange sete anos, é usual para identificar o fenômeno em questão, sendo igual ou até mesmo superior ao adotado em pesquisas anteriores, como de Geng, Bose e Chen (2015) e Kisman e Krisandi (2019). Além disso, os dados coletados iniciam na referência de 2010 (defasagem de um ano nas variáveis de financial distress), período este em que as normas internacionais de contabilidade foram adotadas no Brasil, padronizando a informação. Ressalta-se, ainda, que visando maior comparabilidade, todas as organizações são industriais, pertencentes aos setores, conforme classificação Bovespa, de: 1) bens industriais; 2) consumo cíclico; 3) consumo não cíclico; 4) materiais básicos; 5) petróleo, gás e biocombustíveis; ou, 6) utilidade pública.

Posteriormente, a amostra foi subdividida em dois grupos, sendo eles de empresas familiares e não familiares. A fim de classificar uma determinada empresa como familiar, foi observado os preceitos estabelecidos na literatura, sendo: membros da família possuem 10\% ou mais das ações da corporação, conforme defendem Mok, Lan e Cheung (1992) e Laffranchini e Braun (2014); e/ou, membros da família (dois ou mais) participam da gestão dos negócios, extraído de Anderson e Reeb (2003) e Laffranchini e Braun (2014). Para identificação destas informações, foi consultado no website da Brasil, Bolsa, Balcão (B3) o formulário de referência das companhias. Ao final, 65 empresas $(47,45 \%)$ foram classificadas como familiares 
e 72 empresas (52,55\%) foram delineadas como não familiares. Cabe destacar, por fim, que a coleta de dados abrangeu o período de 2011 a 2017, sendo as informações financeiras extraídas da base de dados Economática ${ }^{\circledR}$.

Para análise dos dados, inicialmente foi elaborada a estatística descritiva das variáveis em estudo, sendo estas de financial distress, estrutura de capital e de controle. Além disso, foi realizado teste de médias (t de Student) para verificar se existem diferenças significativas entre os dois grupos pesquisados no que tange as variáveis numéricas. Por fim, para responder ao objetivo de pesquisa, foram operacionalizados os modelos de regressão logística. Neste sentido, a seguir, apresenta-se o Quadro 1, que contém as variáveis relacionadas ao estudo.

Quadro 1 - Variáveis Dependentes, Independentes e de Controle

\begin{tabular}{|c|c|c|}
\hline Variável & Fórmula ou Descrição & Autores \\
\hline \multicolumn{3}{|c|}{ Variáveis Dependentes - Financial Distress } \\
\hline Financial Distress 1 (FD_1) & $\begin{array}{c}\text { Variável dummy, que recebe valor } \\
1 \text { se o EBITDA - Earnings Before } \\
\text { Interest, Taxes, Depreciation and } \\
\text { Amortization - for insuficiente para } \\
\text { cobrir as despesas financeiras por } \\
\text { dois períodos consecutivos (t e t- } 1 \text {, } \\
\text { no caso) e } 0, \text { caso contrário. }\end{array}$ & $\begin{array}{c}\text { Pindado, Rodrigues e Torre (2008); } \\
\text { Rezende et al. (2017) }\end{array}$ \\
\hline Financial Distress 2 (FD_2) & $\begin{array}{l}\text { Variável dummy, que recebe valor } \\
1 \text { se o fluxo de caixa operacional } \\
\text { gerado for insuficiente para cobrir } \\
\text { as despesas financeiras por dois } \\
\text { períodos consecutivos (t e t- } 1 \text {, no } \\
\text { caso) e } 0 \text {, caso contrário. }\end{array}$ & $\begin{array}{l}\text { Adaptado dos entendimentos } \\
\text { consolidados de Pindado, } \\
\text { Rodrigues e Torre (2008) e Small, } \\
\text { Smidt e Joseph. (2016) }\end{array}$ \\
\hline \multicolumn{3}{|c|}{ Variáveis Independentes - Estrutura de Capital } \\
\hline Endividamento Total (ET) & $\begin{array}{c}\text { Passivo Circulante }+ \\
\frac{\text { Passivo Não Circulante }}{\text { Ativo Total }}\end{array}$ & $\begin{array}{l}\text { Frank e Goyal (2009); Hang et al. } \\
\text { (2017); Abdioğlu (2019) }\end{array}$ \\
\hline $\begin{array}{c}\text { Endividamento de Longo Prazo } \\
\text { (ELP) }\end{array}$ & $\frac{\text { Passivo Não Circulante }}{\text { Ativo Total }}$ & $\begin{array}{l}\text { Frank e Goyal (2009); Abdioğlu } \\
\text { (2019); Lucky e Michael (2019) }\end{array}$ \\
\hline Endividamento Oneroso (EO) & $\begin{array}{l}\text { Passivo Circulante Oneroso + } \\
\frac{\text { Passivo Ñão Circulante Oneroso }}{\text { Ativo Total }}\end{array}$ & $\begin{array}{l}\text { Horta, Alves e Carvalho (2014); } \\
\text { Bezerra, Lagioia e Pereira (2019) }\end{array}$ \\
\hline \multicolumn{3}{|c|}{ Variáveis de Controle - Fatores Específicos das Firmas } \\
\hline Tamanho da Empresa (TAM) & $\begin{array}{c}\text { Logaritmo Natural (LN) da Receita } \\
\text { Líquida de Vendas }\end{array}$ & $\begin{array}{l}\text { Frank e Goyal (2009); Hang et al. } \\
\text { (2017) }\end{array}$ \\
\hline Folga Financeira (FF) & $\frac{\text { Ativo Circulante }}{\text { Passivo Circulante }}$ & $\begin{array}{l}\text { Laffranchini e Braun (2014); } \\
\text { Rezende et al. (2017); Lunardi, Bilk } \\
\text { e Rodrigues Junior (2019) }\end{array}$ \\
\hline Crescimento da Empresa (CE) & $\begin{array}{l}\text { Receita Líquida de Vendas }{ }_{t}- \\
\text { Receita Líquida de Vendas } s_{t-1} \\
\text { Rceita Líquida de Vendas } \text { Ven }_{t-1}\end{array}$ & Hang et al. (2017); Abdioğlu (2019) \\
\hline \multicolumn{3}{|c|}{ Variáveis de Controle - Fator Macroeconômico } \\
\hline Produto Interno Bruto (PIB) & $\begin{array}{c}\text { \% médio de crescimento ou } \\
\text { decréscimo do PIB nos períodos de } \\
\text { t e t-1 no Brasil conforme dados } \\
\text { extraídos do Banco Mundial } \\
\text { (World Bank) }\end{array}$ & $\begin{array}{l}\text { Frank e Goyal (2009); Rezende et } \\
\text { al. (2017); Gottardo e Moisello } \\
\text { (2019) }\end{array}$ \\
\hline
\end{tabular}

Observação: por "oneroso", entende-se empréstimos e financiamento e debêntures, de curto e longo prazo, que geram despesas financeiras.

Fonte: dados da pesquisa.

Fazendo uso das variáveis apresentadas no Quadro 1, foram elaborados os modelos de regressão logística. Desta forma, segue abaixo as equações utilizadas para verificar a influência da estrutura de capital no financial distress em empresas familiares e não familiares brasileiras.

$$
\begin{aligned}
& D F_{-} 1=\beta_{0}+\beta_{1} E T+\beta_{2} E L P+\beta_{3} E O+\beta_{4} T A M+\beta_{5} F F+\beta_{6} C E+\beta_{7} P I B+\varepsilon \\
& D F_{-} 2=\beta_{0}+\beta_{1} E T+\beta_{2} E L P+\beta_{3} E O+\beta_{4} T A M+\beta_{5} F F+\beta_{6} C E+\beta_{7} P I B+\varepsilon
\end{aligned}
$$

Equação 1

Equação 2 
Conforme as equações, a pesquisa terá os modelos relacionados às variáveis dependentes FD_1 e DF_2, que contemplam formas distintas de dimensionar a situação de dificuldades financeiras nas empresas, sendo estas operacionalizadas em separado para empresas familiares e não familiares. O dimensionamento de modelos individuais para empresas familiares e não familiares no tema financial distress pode ser observado na referência Gottardo e Moisello (2019). Ainda, ressalta-se que foram observados os pressupostos estatísticos para a aplicação dos modelos de regressão logística, ao se executar, especificamente, os testes de Omnibus e de Hosner e Lemeshow, além da Variance Inflation Factor (VIF). Por fim, destaca-se que os dados foram tabulados em planilhas eletrônicas e os modelos econométricos foram realizados com auxílio do software SPSS versão 21.

\section{Descrição e Análise dos Dados}

Nesta seção apresenta-se inicialmente os resultados vinculados à estatística descritiva das variáveis, tanto das categóricas quanto das numéricas, contemplando, ainda, o teste de médias para as últimas, a fim de verificar se há diferenças significativas entre empresas familiares e não familiares. Assim, segue Tabela 1 para posterior inferências.

Tabela 1 - Estatística Descritiva e Teste de Média das Variáveis

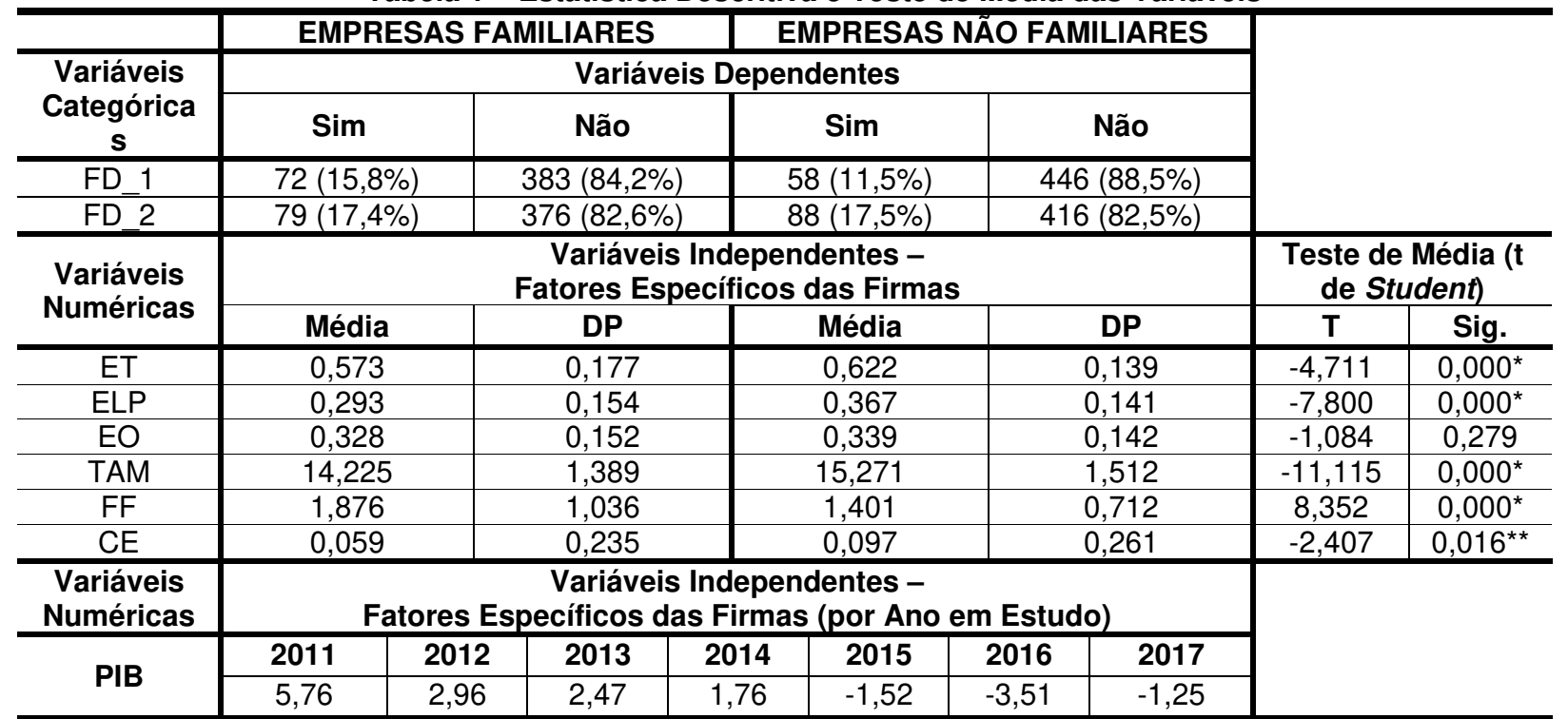

Observações: 1) nas variáveis dependentes, avaliadas por FD_1 e FD_2, o termo "Sim" representa as observações de empresas em financial distress, enquanto o termo "Não" representa as observações de empresas saudáveis financeiramente; e, 2) conforme informado previamente no Quadro 1, o PIB do ano de referência é composto pela média do período atual (t) com o do período anterior (t-1). Tal procedimento foi adotado visando conciliar temporalmente a referida variável de controle macroeconômica com as variáveis dependentes de financial distress.

Legenda: FD_1 - Financial Distress 1; FD_2 - Financial Distress 2; ET - Endividamento Total; ELP - Endividamento de Longo Prazo; EO - Endividamento Oneroso; TAM - Tamanho da Empresa; FF - Folga Financeira; CE - Crescimento da Empresa; e, PIB - Produto Interno Bruto.

*Significância ao Nível de 1\%; ** Significância ao Nível de 5\%.

Fonte: dados da pesquisa.

Mediante Tabela 1, é possível observar que das variáveis categóricas de financial distress, a FD_2 apresenta, em ambos os grupos de empresas, maior proporção de organizações classificadas como em dificuldades financeiras. Precisamente, entre as empresas familiares, pela métrica de FD_1, 15,8\% das organizações foram enquadradas como em dificuldades financeiras, contra 17,4\% na métrica de FD_2. Por sua vez, nas empresas não familiares, $11,5 \%$ das empresas foram classificadas como em financial distress pela métrica FD_1, contra 17,5\% quando operacionalizadas pela FD_2.

É importante salientar as diferenças entre as métricas utilizadas de financial distress a fim de compreender a maior proporção de empresas assim classificadas em face a operacionalização de FD_2. Pontualmente, FD_1 parte de uma lógica econômica, visto que o numerador é dado pelo EBITDA, extraído da Demonstração do Resultado do Exercício (DRE), enquanto o denominador é representado pelas despesas financeiras. A lógica subjacente ao EBITDA é de que este represente a geração operacional de caixa de uma organização, todavia, por ser extraído da DRE, é dimensionado sob o regime de competência. Por sua vez, a métrica FD_2, em vez de partir de uma condição econômica, utiliza propriamente o caixa operacional gerado no período, extraído da Demonstração do Fluxo de Caixa (DFC), sendo que este deve acobertar as despesas financeiras para que a organização esteja solvente financeiramente. 
Logo, menciona-se que a limitação do EBITDA perpassa pela falsa ideia de liquidez que a empresa consegue apresentar em alguns casos. Uma organização pode efetuar vendas a clientes que não serão recebidas (problemas na análise de concessão de crédito), sendo capaz de apresentar EBITDA suficiente para cobrir as despesas financeiras, mas que, de fato, não há dinheiro em caixa para tanto. Desta forma, o EBITDA, por partir de uma lógica econômica dada por regime de competência, pode ser limitante na análise de dificuldades financeiras, mesmo que estudos anteriores tenham utilizado esta métrica, como é o caso de Pindado, Rodrigues e Torre (2008).

Neste contexto, a análise de "FD_2" é subjacente à tentativa de mitigar tal limitação. A utilização do fluxo de caixa operacional do período demonstra se de fato os eventos operacionais que afetaram o caixa são suficientes, pelo menos, para remunerar o capital de terceiros (despesas financeiras). Pelos custos e despesas operacionais (e passivos) que representam saídas de caixa tenderem a ser mais líquidos e certos do que as receitas (e ativos) que representam entradas de caixa, torna-se natural que em "FD_2", número superior de empresas apresente dificuldades financeiras, como observado em ambos os grupos de empresas.

Com base nas argumentações expostas, enfatiza-se que é primordial a utilização de medidas diversificadas de financial distress, sobretudo em pesquisas que visam à identificação de seus determinantes, a fim de verificar a complacência destes com as variadas métricas de dificuldades financeiras corporativas. Ademais, quanto as variáveis independentes numéricas atreladas ao teste de médias, tem-se que das seis medidas operacionalizadas, sendo três delas de estrutura de capital e outras três de controle, em cinco casos existem diferenças significativas entre empresas familiares e não familiares.

Em análise separada dos indicadores, tem-se inicialmente que empresas familiares, nos três níveis de estrutura de capital estudados, apresentam endividamento médio inferior ao de empresas não familiares. Todavia, cabe destacar que dentre estes, apenas dois deles são significativamente diferentes entre as subamostras de empresas, sendo o endividamento total e o endividamento de longo prazo. $O$ endividamento oneroso, por sua vez, apesar de ser inferior em empresas não familiares, não é estatisticamente diferente ao das empresas familiares. Majoritariamente, os achados evidenciados para o contexto brasileiro corroboram com os observados no cenário da Europa Ocidental por Santos, Moreira e Vieira (2014), de que em companhias com propriedade mais concentrada (caracterizadas como familiares), o endividamento é inferior.

Além destes resultados serem consonantes com pesquisas empíricas anteriores, conceitos teóricos também suportam que empresas familiares tendem a apresentar níveis de endividamento inferiores a suas contrapartes não familiares. Kayo, Brunaldi e Aldrighi (2018) defendem que usar dívida para financiar projetos tende a aumentar o risco de falência de uma empresa, prejudicando os acionistas, o que, por consequência, aumenta a probabilidade de que a família controladora (caracterizada como familiar) seja forçada a abandonar o controle da empresa. Logo, para não se expor demasiadamente a este risco, torna-se natural pressupor que empresas familiares tenham apetite contrário ao aumento da dívida.

Quanto as variáveis de controle, observou-se, por médias, que empresas familiares possuem menor porte, apresentam mais folga financeira e crescem de forma menos impactante em comparação às empresas não familiares, sendo todas estas inferências significativas estatisticamente. Como fatores explicativos, busca-se as prerrogativas dadas por Kayo, Brunaldi e Aldrighi (2018), que baseando-se em pesquisas anteriores, mencionam que mesmo que o baixo endividamento prejudique o crescimento de organizações familiares, dado a limitação imposta de captação de recursos via terceiros, estas ainda assim preferem não utilizar a dívida em patamares elevados. Por tal pressuposto, torna-se entendível o menor tamanho das organizações familiares, bem como o seu crescimento mais lento comparativamente as empresas não familiares.

De forma similar, pelas empresas familiares serem avessas ao risco (SANTOS; MOREIRA; VIEIRA, 2014), é natural pressupor que estas operem, em média, com níveis mais elevados de folga financeira, uma vez que tais recursos em excesso possuem potencial de proporcionar maior resiliência corporativa a choques externos, auxiliando, portanto, a estabilidade da empresa ao longo do tempo. Empiricamente, resultados similares foram observados no cenário brasileiro por Pamplona et al. (2019). De acordo com tais autores, tal prática é impulsionada pela visão de longo prazo das empresas familiares, que visam a prosperidade empresarial por várias gerações da família empreendedora. Por fim, quanto a variável PIB, nota-se que nos períodos mais recentes estudados têm-se os piores indicadores, estando alinhado a recente crise que assolou o Brasil, sobretudo nos anos de 2015 e 2016.

Vistos e analisados os resultados vinculados à estatística descritiva e ao teste de médias, apresentase, na sequência, mediante Tabela 2, os resultados da regressão logística, que visam responder ao objetivo de pesquisa previamente elaborado. Observam-se os fatores explicativos para que as organizações familiares e não familiares estejam em financial distress. Todavia, antes de adentrar a análise individual dos resultados, é essencial compreender as principais características dos modelos de regressão logística. Logo, inicialmente tem-se que nos quatro modelos operacionalizados, a estatística Wald foi significativa $($ sig. $<0,05)$, o que conforme Ritta, Gorla e Hein (2015), demonstra que a variável constante do modelo de regressão contribui para formular previsões ao objeto de interesse (RITTA; GORLA; HEIN, 2015), permitindo inferências.

Ademais, de acordo com Gonçalves, Gouvêa e Mantovani (2013), há dois testes principais a se observar em regressões logísticas, sendo estes: teste de Omnibus e teste de Hosner e Lemeshow. Tais testes permitem analisar, posteriormente a inclusão das variáveis independentes estudadas, se o modelo é capaz 
de realizar as predições com a acurácia necessária. Em análise, quanto menor o valor do teste de Omnibus, maior a qualidade do ajuste (GONÇALVES; GOUVÊA; MANTOVANI, 2013). Por nesta pesquisa todos os modelos apresentarem sig. de 0,000, estes são satisfatórios.

Tabela 2 - Influência da Estrutura de Capital no Financial Distress em Empresas Familiares e Não Familiares Brasileiras

\begin{tabular}{|c|c|c|c|c|c|c|c|c|}
\hline \multirow{3}{*}{ Variáveis } & \multicolumn{4}{|c|}{ EMPRESAS FAMILIARES } & \multicolumn{4}{|c|}{ EMPRESAS NÂO FAMILIARES } \\
\hline & \multicolumn{2}{|c|}{ FD 1} & \multicolumn{2}{|c|}{ FD 2} & \multicolumn{2}{|c|}{ FD 1} & \multicolumn{2}{|c|}{ FD 2} \\
\hline & Coef. & Sig. & Coef. & Sig. & Coef. & Sig. & Sig. & Coef. \\
\hline ET & 12,077 & $0,000^{*}$ & 11,504 & $0,000^{*}$ & 5,120 & $0,001^{*}$ & 1,935 & 0,154 \\
\hline ELP & $-2,950$ & $0,024^{\star *}$ & $-4,609$ & $0,001^{*}$ & $-6,571$ & $0,000^{*}$ & $-4,401$ & $0,001^{*}$ \\
\hline $\mathrm{EO}$ & $-3,968$ & $0,020^{* *}$ & $-4,747$ & $0,005^{*}$ & 1,324 & 0,357 & 3,031 & $0,018^{\star *}$ \\
\hline TAM & $-0,570$ & $0,000^{*}$ & $-0,389$ & $0,006^{*}$ & ---- & --- & --- & ---- \\
\hline FF & 0,288 & 0,127 & $-0,262$ & 0,295 & $-0,287$ & 0,323 & $-0,026$ & 0,896 \\
\hline $\mathrm{CE}$ & $-0,672$ & 0,351 & $-0,251$ & 0,697 & $-0,005$ & 0,994 & 0,043 & 0,928 \\
\hline PIB & $-0,179$ & $0,001^{*}$ & $-0,154$ & $0,004^{*}$ & $-0,106$ & $0,044^{* *}$ & $-0,136$ & $0,002^{*}$ \\
\hline CONS & 0,801 & 0,662 & 0,400 & 0,824 & $-3,012$ & $0,003^{*}$ & $-2,130$ & $0,007^{*}$ \\
\hline $\begin{array}{c}\text { Variáveis da Equação } \\
\text { (Constante) - Wald }\end{array}$ & \multicolumn{2}{|c|}{$0,000^{*}$} & \multicolumn{2}{|c|}{$0,000^{*}$} & \multicolumn{2}{|c|}{$0,000^{*}$} & \multicolumn{2}{|c|}{$0,000^{*}$} \\
\hline $\begin{array}{l}\text { Teste Omnibus (Etapa; } \\
\text { Bloco; Modelo) }\end{array}$ & \multicolumn{2}{|c|}{$0,000^{*}$} & \multicolumn{2}{|c|}{$0,000^{*}$} & \multicolumn{2}{|c|}{$0,000^{*}$} & \multicolumn{2}{|c|}{$0,000^{*}$} \\
\hline $\begin{array}{l}\text { Teste de Hosmer e } \\
\text { Lemeshow }\end{array}$ & \multicolumn{2}{|c|}{0,555} & \multicolumn{2}{|c|}{0,213} & \multicolumn{2}{|c|}{0,599} & \multicolumn{2}{|c|}{0,088} \\
\hline Verosimilhança & \multicolumn{2}{|c|}{309,138} & \multicolumn{2}{|c|}{316,946} & \multicolumn{2}{|c|}{322,574} & \multicolumn{2}{|c|}{438,482} \\
\hline pseudo-R $\mathrm{R}^{2}$ Cox e Snell & \multicolumn{2}{|c|}{0,176} & \multicolumn{2}{|c|}{0,203} & \multicolumn{2}{|c|}{0,071} & \multicolumn{2}{|c|}{0,055} \\
\hline pseudo-R ${ }^{2}$ Nagelkerke & \multicolumn{2}{|c|}{0,303} & \multicolumn{2}{|c|}{0,336} & \multicolumn{2}{|c|}{0,140} & \multicolumn{2}{|c|}{0,091} \\
\hline $\begin{array}{l}\text { VIF (Variance Inflation } \\
\text { Factor) }\end{array}$ & \multicolumn{2}{|c|}{$<4,51$} & \multicolumn{2}{|c|}{$<4,51$} & \multicolumn{2}{|c|}{$<2,51$} & \multicolumn{2}{|c|}{$<2,51$} \\
\hline Nr. de Observações & & & & & & & & \\
\hline
\end{tabular}

Legenda: FD_1 - Financial Distress 1; FD_2 - Financial Distress 2; ET - Endividamento Total; ELP - Endividamento de Longo Prazo; EO - Endividamento Oneroso; TAM - Tamanho da Empresa; FF - Folga Financeira; CE - Crescimento da Empresa; PIB - Produto Interno Bruto; e, CONS - Constante.

*Significância ao nível de 1\%; **Significância ao nível de $5 \%$.

Fonte: dados da pesquisa.

Já quanto ao teste de Hosner e Lemeshow, Ritta, Gorla e Hein (2015) mencionam que este deve apresentar sig. acima de 0,05 para que os valores previstos não sejam significativamente diferentes dos observados. Logo, todos os quatro modelos operacionalizados foram bem dimensionados quanto ao referido teste. Cabe destacar, contudo, que nos modelos das empresas não familiares, para que o referido teste fosse aceito, teve-se que retirar a variável tamanho da empresa. Por se tratar de um fator de controle, adotou-se este procedimento, visto que o foco principal da pesquisa, que é verificar a influência da estrutura de capital no financial distress em empresas familiares e não familiares brasileiras, permanece inalterado.

Os pseudos- $\mathrm{R}^{2}$ de Cox \& Snell e de Nagelkerke avaliam o desempenho geral do modelo para prever o financial distress corporativo. Os resultados destes evidenciam a proporção das variações ocorridas na variável financial distress (dependente) que é explicada pelas variações ocorridas nas variáveis independentes do modelo de regressão logística (RITTA; GORLA; HEIN., 2015). Neste sentido, tem-se que nos modelos para empresas familiares alcançou-se poder explicativo bastante superior, o que pode estar vinculado a dois aspectos, sendo eles a presença adicional da variável tamanho, bem como a maior importância das variáveis de estudo para empresas familiares, o que maximiza a observância destas por gestores familiares a fim de manter as organizações que administram saldáveis financeiramente. Por fim, o VIF, sempre abaixo de 5 , aponta que não há problemas de multicolinearidade entre as variáveis testadas.

Em referência aos resultados obtidos que constam na Tabela 2, tem-se, de forma geral, que os diferentes níveis de endividamento estudados afetam de forma diferente a probabilidade de uma empresa entrar em financial distress, com alteração também entre empresas familiares e não familiares para uma das variáveis em estudo, sendo esta o endividamento oneroso. Precisamente, o endividamento total influencia positivamente a probabilidade de as empresas entrarem em financial distress, enquanto o endividamento de longo prazo apresenta influência negativa, sendo tais resultados, majoritariamente significativos, evidenciados tanto para empresas familiares como para suas contrapartes não familiares.

Para a compreensão dos resultados descritos, ambas as teorias de estrutura de capital - trade-off $e$ pecking-order - apresentam subsídios importantes. A geração de caixa capturada como fator de financial distress é derivada do EBITDA (DRE) e do fluxo de caixa operacional (DFC) e, desta forma, ambas estão vinculadas ao bom desempenho econômico corporativo, mesmo que possa haver flutuações, sobretudo na segunda métrica, quanto a realização dos eventos operacionais. Partindo disto, a pecking-order theory, que defende a empresa como utilizando, em primeira instância, financiamento interno (MYERS, 1984) pode explicar a relação positiva entre endividamento total e financial distress, enquanto a trade-off theory, em que 
o uso do capital de terceiros seria vantajoso ao reduzir o custo de capital mediante benefícios fiscais da dívida (MODIGLIANI; MILLER, 1963) é condizente com a relação negativa entre a dívida de longo prazo e o financial distress.

Além dos aspectos teóricos, resultados empíricos vinculados à estrutura de capital têm apresentado que os variados níveis de endividamento podem afetar de forma diferente o desempenho corporativo e, por consequência, a probabilidade de uma organização entrar em financial distress. A efeito, Vãtavu (2015) notou, no contexto romeno, que o endividamento de curto prazo e o endividamento total tem relação negativa com a performance corporativa, enquanto que o endividamento de longo prazo apresentou resultados variados e inconclusivos, sugerindo, portanto, característica diferente a ser melhor observada.

Partindo do estudo de Vãtavu (2015), os resultados desta pesquisa, sob a metodologia adotada de influência da estrutura de capital na probabilidade de financial distress, podem ser considerados congruentes. $O$ endividamento de longo prazo, em que a organização possui maior tempo para honrar com seus compromissos, tende a ser benéfico financeiramente a empresa, visto que pode ser utilizado para financiar investimentos que gerarão resultados futuros, possivelmente suficientes para cobrir as obrigações para com terceiros e, ainda, financiar os interesses dos acionistas, o que justifica a relação negativa entre dívida de longo prazo e financial distress.

Em contrapartida, dívidas de curto prazo, incluídas na variável de endividamento total, além de terem exigibilidade reduzida em lapso temporal, geralmente financiam aspectos operacionais e não de investimentos, como fornecedores, salários a pagar, tributos a recolher, etc. Logo, é de se esperar que organizações que apresentam dificuldades de honrar suas dívidas para com estas partes, aumentando substancialmente o endividamento de curto prazo e, consequentemente, o endividamento total, tendem a apresentar maior propensão ao financial distress, justificando, portanto, a relação positiva entre dívida total e financial distress.

Além da consideração dos sinais, é essencial a análise acerca da magnitude dos coeficientes em questão, sobretudo quanto ao endividamento total que apresenta maior impacto. Especificamente, observase na Tabela 2 que os coeficientes de ET são superiores ao dobro em empresas familiares comparativamente às suas contrapartes não familiares. Isso significa que o alto endividamento total eleva a probabilidade de organizações familiares adentrarem ao financial distress de forma muito expressiva. Tal fato tende a estar vinculado a aversão ao risco de corporações do tipo familiar, que ao se depararem com o alto endividamento total e, portanto, ao alto risco, não sabem lidar com a situação, o que as expõem ainda mais ao financial distress. Cabe relembrar que dentro desta variável, as dívidas de curto prazo estão inseridas, rubrica esta, que se mal dimensionada, tende a asfixiar mais facilmente a solidez financeira corporativa.

Quanto à terceira medida de estrutura de capital, sendo o endividamento oneroso, observou-se uma particularidade, em que o EO apresenta relação diferente para com empresas familiares e não familiares. A dívida onerosa afeta negativamente e de forma significativa a probabilidade de financial distress de empresas familiares, enquanto a relação é positiva para com as empresas não familiares (e apenas significativa para a medida dependente FD_2). Tais resultados, no que concerne ao endividamento oneroso, são condizentes com a trade-off theory para empresas familiares e com a pecking-order theory para as empresas não familiares.

Os resultados descritos podem ser explicados por fatores evidenciados em estudos anteriores. A reconhecida pesquisa de Anderson, Mansi e Reeb (2003) encontrou que a propriedade familiar está relacionada, estatisticamente e economicamente, a um custo menor de dívida (ANDERSON; MANSI; REEB., 2003). De fato, a relação da família para com os credores pode trazer credibilidade à empresa, que usufruirá de recursos mais acessíveis junto a terceiros, o que justifica o endividamento oneroso, que possui juros atrelados, ser mais benéfico a empresas familiares comparativamente às empresas não familiares, influenciando, por consequência, de forma diferente na probabilidade de financial distress corporativo.

Além disso, como empresas familiares tendem a ser mais avessas a decisões financeiras arriscadas (SANTOS; MOREIRA; VIEIRA, 2014), é natural que estas apenas irão aumentar o EO caso apresentem projetos de investimentos com baixo risco, que garantam a solvência financeira da empresa, resguardando 0 nome da família e a sobrevivência da companhia no longo prazo. Em contrapartida, organizações não familiares tendem a possuir pré-disposição de arriscar em projetos incertos, o que justifica a não quitação do endividamento caso estes projetos não se consolidem, levando as empresas ao financial distress. Com base no exposto, a diferença do endividamento oneroso ser negativamente relacionado ao financial distress em organizações familiares e positivamente em empresas não familiares pode, além do custo da dívida, estar atrelado ao apetite a risco de cada uma delas, em que a linearidade das decisões financeiras das famílias quanto à dívida onerosa tende a sobressair-se.

Por resultados agregados, não se rejeita a hipótese de pesquisa $H_{1}$ - existe relação entre a estrutura de capital e o financial distress em empresas brasileiras, sendo esta diferente para empresas familiares comparativamente a suas contrapartes não familiares. Tais resultados corroboram com evidencias anteriores observadas em outros cenários, como por Lucky e Michael (2019) na Nigéria, que constataram que a estrutura de capital tem efeito significativo sobre os problemas financeiros das empresas e Gottardo e Moisello (2019) na Itália, que afirmam que variáveis contábeis/financeiras e macroeconômicas apresentam significados diferentes a fim de explicar o financial distress em empresas familiares e não familiares (GOTTARDO; 
MOISELLO, 2019), evidência esta aqui comprovada no contexto brasileiro, com ênfase comparativa e inovadora para múltiplas medidas de estrutura de capital.

Finalmente, quanto as variáveis de controle, observa-se que empresas familiares de menor porte possuem maior probabilidade de financial distress, enquanto PIBs inferiores também elevam a probabilidade das empresas, neste caso tanto familiares como não familiares, de adentrar ao financial distress. Já às variáveis folga financeira e crescimento da empresa, em nenhum dos modelos operacionalizados apresentaram significância estatística, não sendo, portanto, determinantes do financial distress de empresas familiares e não familiares brasileiras.

\section{Considerações Finais}

O presente estudo objetivou verificar a influência da estrutura de capital no financial distress em empresas familiares e não familiares brasileiras. Para consecução deste objetivo, foi realizada pesquisa descritiva, de procedimento documental e de abordagem quantitativa dos dados. A amostra de estudo abrangeu 137 empresas, sendo 65 familiares e 72 não familiares, com dados abarcando o período de 2011 a 2017. Quanto às técnicas estatísticas utilizadas, tem-se estatística descritiva, teste de médias (t de student) e regressão logística.

Foi verificado, mediante estatística descritiva e teste de médias, que a forma como as empresas familiares e não familiares captam recursos é estatisticamente diferente no cenário brasileiro. Precisamente, observou-se que as empresas não familiares tendem a utilizar com maior intensidade capital de terceiros comparativamente as organizações familiares, sendo tal fato condizente com a perspectiva teórica de que empresas familiares possuem visão de longo prazo e, portanto, são avessas a dívida por esta representar maior risco. Ainda assim, as duas medidas de financial distress utilizadas apontam que a proporção de empresas familiares e não familiares que entram em dificuldades financeiras é similar.

Quanto aos resultados atrelados à regressão logística, principais da pesquisa, observou-se que alguns pontos são convergentes e outros divergentes para empresas familiares e não familiares. No que convergem, tem-se que para ambos os tipos de organizações, o endividamento total afeta positivamente a probabilidade de financial distress, enquanto o endividamento de longo prazo influência de forma negativa. Estes achados são de primordial importância, pois sugerem que os diferentes tipos de dívida devem ser interpretados de forma particular pelas partes interessadas a fim de detectar potenciais empresas que enfrentam financial distress.

Em reflexão, o endividamento de longo prazo, por geralmente estar atrelado a investimentos que irão gerar caixa nos períodos subsequentes, facilita a saúde financeira corporativa. Em contrapartida, 0 endividamento total, que agrega adicionalmente dívidas de curto prazo, demonstrou-se prejudicial à geração de recursos financeiros e, portanto, intensifica a probabilidade de financial distress corporativo. Como conclusão, para investidores mais conservadores e para aqueles interessados na distribuição de dividendos, a observância do endividamento total deve ser feita com precisão, pois níveis elevados de dívida deste tipo aumentam a probabilidade do não cumprimento da empresa para com seus compromissos, o que deve impactar tanto no valor das ações como na probabilidade de efetivar dividendos.

Por sua vez, o endividamento oneroso apresentou sinal oposto para empresas familiares e não familiares e, portanto, deve ser interpretado por gestores, investidores e outras partes interessadas de forma distinta, dependendo do tipo de organização. Efetivamente, tem-se que o endividamento oneroso afeta negativamente a probabilidade de financial distress em empresas familiares, mas aumenta a probabilidade para as não familiares. Este tipo de endividamento gera juros, em que empresas familiares, por gozarem de credibilidade no mercado mediante sua imagem e serem menos endividadas, tendem a usufruir de capital de terceiros a um custo mais baixo do que empresas não familiares.

Logo, os resultados vinculados ao endividamento oneroso sugerem que gestores de organizações familiares melhor usufruem desta fonte de recursos para consecução de investimentos e objetivos organizacionais. Em contrapartida, gestores de empresas não familiares precisam ser mais moderados na utilização de capital de terceiros a fim de não se expor demasiadamente aos custos de embaraço financeiro que levam, por consequência, ao financial distress. De similar análise, investidores devem observar o endividamento oneroso de acordo com seus apetites a risco a fim de tomar decisões mais assertivas para maximizar o retorno de seus investimentos, fugindo, sobretudo, de empresas potenciais a se tornarem insolventes financeiramente.

Em vista dos fatores observados e descritos, a contribuição desta pesquisa perpassa pelas descobertas que os distintos tipos de endividamento afetam de forma diferente a probabilidade de financial distress das corporações e da existência de variações quanto ao tipo de empresa, se familiar ou não familiar. Inúmeros pesquisadores focam nos potenciais efeitos do endividamento no financial distress corporativo de forma genérica, negligenciando a maturidade da dívida. De forma similar, inúmeras pesquisas acerca do fenômeno não consideram a propriedade e gestão corporativa. Com base nos achados aqui observados, novos insights são oferecidos a literatura, bem como a advertência para que pesquisas futuras sejam realizadas contemplando diferenciais metodológicos robustos. 
Contudo, apesar de trazer insights importantes para inúmeras partes interessadas, com modelos validados estatisticamente, os resultados desta pesquisa devem ser interpretados com cautela, dado a existência de limitações intrínsecas a pesquisas deste tipo. As métricas escolhidas para dimensionar o financial distress são duas de incontáveis existentes. Mesmo com levantamento literário, não se pode afirmar que tais variáveis melhor representam a situação de financial distress nas empresas brasileiras. Portanto, os resultados obtidos devem ser interpretados no cerne dos modelos adotados e perante a metodologia posta.

Dada a complexidade do tema em estudo, abre-se a possibilidade de desenvolvimentos futuros. Assim, sugere-se a replicação desta pesquisa no Brasil considerando, como diferencial, outras métricas de financial distress, com vistas a comparação dos achados aqui observados. Pesquisadores podem também investigar o fenômeno em questão em outros países, sobretudo emergentes, a fim de comparar os resultados entre nações e estabelecer potenciais fatores que justifiquem semelhanças ou diferenças encontradas, com ênfase aos aspectos macroeconômicos. Possibilidades são amplas e cabe a pesquisadores adentrarem ao desenvolvimento de tais pesquisas, com rigor e robustez metodológica, a fim de elevar o conhecimento sobre financial distress corporativo.

\section{Referências}

ABDIOĞLU, N. The impact of firm specific characteristics on the relation between financial distress and capital structure decisions. Journal of Business Research-Turk, v. 11, n. 2, p. 1057-1067, 2019. DOI: https://doi.org/10.20491/isarder.2019.655

ALTMAN, E. I. Financial ratios, discriminant analysis and the prediction of corporate bankruptcy. The Journal of Finance, v. 23, n. 4, p. 589-609, 1968. DOI: https://doi.org/10.1111/j.1540-6261.1968.tb00843.x

ANDERSON, R. C.; DURU, A.; REEB, D. M. Investment policy in family-controlled firms. Journal of Banking and Finance, v. 36, n. 6, p. 1744-1758, 2012. DOI: https://doi.org/10.1016/j.jbankfin.2012.01.018

ANDERSON, R. C.; MANSI, S. A.; REEB, D. M. Founding family ownership and the agency cost of debt. Journal of Financial Economics, v. 68, n. 2, p. 263-285, 2003. DOI: https://doi.org/10.1016/S0304405X(03)00067-9

ANDERSON, R. C.; REEB, D. M. Founding-family ownership and firm performance: Evidence from the S\&P 500. The Journal of Finance, v. 58, n. 3, p. 1301-1328, 2003. DOI: https://doi.org/10.1111/15406261.00567

ASQUITH, P.; GERTNER, R.; SCHARFSTEIN, D. Anatomy of financial distress: An examination of junkbond issuers. The Quarterly Journal of Economics, v. 109, n. 3, p. 625-658, 1994. DOI: https://doi.org/10.2307/2118416

ATAÜNAL, L.; AYBARS, A. Testing target-adjustment and pecking order models of capital structure and estimating speed of adjustment: Evidence from Borsa Istanbul (BIST). International Journal of Corporate Finance and Accounting, v. 4, n. 1, p. 1-15, 2017. DOI: https://doi.org/10.4018/lJCFA.2017010101

BANCO MUNDIAL (WORLD BANK). World development indicators. Disponível em: http://data.worldbank.org/indicator/NY.GDP.MKTP.KD.ZG. Acesso em: 09 jul. 2018.

BEAVER, W. H. Financial ratios as predictors of failure. Journal of Accounting Research, v. 4, n. 1, p. 71111, 1966. DOI: https://doi.org/10.2307/2490171

BEZERRA, E. S.; LAGIOIA, U. C. T.; PEREIRA, M. de L. Financial, macroeconomic and corporative management indicators to predict the insolvency of B3 companies. Journal of Accounting, Management and Governance, v. 22, n. 3, p. 405-422, 2019. DOI: http://dx.doi.org/10.21714/1984-3925_2019v22n3a6

DUMONT, G.; SCHMIT, M. Tier-1 MFIs' financial performance: Cash-flow statement analysis version 2.0. Working Paper. In: Research Institute in Management Sciences, v. 1413, n. 54, p. 1-36, 2014. Disponível em: https://www.semanticscholar.org/paper/Tier-1-MFIs-Financial-Performance\%3A-Cash-flow-DumontSchmit/5263757283743ace0792a3f1f8eff6778e60e6db. Acesso em: 11 jul. 2018.

FRANK, M. Z.; GOYAL, V. K. Capital structure decisions: Which factors are reliably important? Financial Management, v. 38, n. 1, p. 1-37, 2009. DOI: https://doi.org/10.1111/j.1755-053X.2009.01026.x

GENG, R.; BOSE, I.; CHEN, X. Prediction of financial distress: An empirical study of listed chinese companies using data mining. European Journal of Operational Research, v. 241, n. 1, p. 236-247, 2015. DOI: https://doi.org/10.1016/j.ejor.2014.08.016 
GONÇALVES, E. B.; GOUVÊA, M. A.; MANTOVANI, D. M. N. Análise de risco de crédito com o uso de regressão logística. Revista Contemporânea de Contabilidade, v. 10, n. 20, p. 139-160, 2013. DOI: https://doi.org/10.5007/2175-8069.2013v10n20p139

GOTTARDO, P.; MOISELLO, A. M. Family influence, leverage and probability of financial distress. In. Capital Structure, Earnings Management, and Risk of Financial Distress. SpringerBriefs in Business, 2019, p.41-55. DOI: https://doi.org/10.1007/978-3-030-00344-9_3

HANG, M.; GEYER-KLINGEBERG, J.; RATHGEBER, A. W.; STÖCKL, S. Measurement matters - A metastudy of the determinants of corporate capital structure. The Quarterly Review of Economics and Finance, v. 68, n. 1, p. 211-225, 2017. DOI: https://doi.org/10.1016/j.qref.2017.11.011

HORTA, R. A. M.; ALVEZ, F. J. dos S.; CARVALHO, F. A. A. de. Seleção de atributos na previsão de insolvência: Aplicação e avaliação usando dados brasileiros recentes. Revista de Administração Mackenzie, v. 15, n. 1, p. 125-151, 2014.

KAHL, M. (2002). Economic distress, financial distress, and dynamic liquidation. The Journal of Finance, v. 57, n. 1, p. 135-168, 2002. DOI: https://doi.org/10.1111/1540-6261.00418

KAYO, E. K.; BRUNALDI, E. O.; ALDRIGHI, D. M. Capital structure adjustment in Brazilian family firms. Revista de Administração Contemporânea, v. 22, n. 1, p. 92-114, 2018. DOI:

https://doi.org/10.1590/1982-7849rac2018170004

KISMAN, Z.; KRISANDI, D. How to predict financial distress in the wholesale sector: Lesson from Indonesian Stock Exchange. Journal of Economics and Business, v. 2, n. 3, p. 569-585, 2019. DOI:

https://doi.org/10.31014/aior.1992.02.03.109

LAFFRANCHINI, G.; BRAUN, M. Slack in family firms: Evidence from Italy (2006-2010). Journal of Family Business Management, v. 4, n. 2, p. 171-193, 2014. DOI: https://doi.org/10.1108/JFBM-04-2013-0011

LUCKY, L. A.; MICHAEL, A. O. Leverage and corporate financial distress in Nigeria: A panel data analysis. Asian Finance \& Baking Review, v. 3, n. 2, p. 26-38, 2019. DOI: https://doi.org/10.46281/asfbr.v3i2.370

LUNARDI, M. A.; BILK, Â.; RODRIGUES JUNIOR, M. M. Financial distress e o desempenho econômico, de mercado e financeiro. Revista Contabilidade Vista \& Revista, v. 31, n. 1, p. 85-104, 2020. DOI: https://doi.org/10.22561/cvr.v31i1.4853

MODIGLIANI, F.; MILLER, M. H. Corporate income taxes and the cost of capital: A correction. The American Economic Review, v. 53, n. 3, p. 433-443, 1963. Disponível em: https://www.jstor.org/stable/1809167?seq=1. Acesso em: 13 jul. 2018.

MODIGLIANI, F.; MILLER, M. H. The cost of capital, corporation finance and the theory of investment. The American Economic Review, v. 48, n. 3, p. 261-297, 1958. Disponível em: https://www.jstor.org/stable/1809766?seq=1. Acesso em: 13 jul. 2018.

MOK, H. M.; LAM, K.; CHEUNG, I. Family control and return covariation in Hong Kong's common stocks. Journal of Business Finance \& Accounting, v. 19, n. 2, p. 277-293, 1992. DOI: https://doi.org/10.1111/j.1468-5957.1992.tb00625.x

MYERS, S. C. The capital structure puzzle. The Journal of Finance, v. 39, n. 3, p. 574-592, 1984. DOI: https://doi.org/10.1111/j.1540-6261.1984.tb03646.x

NIGAM, N.; BOUGHANMI, A. Can innovative reforms and practices efficiently resolve financial distress? Journal of Cleaner Production, v. 140, n. 3, p. 1860-1871, 2017. DOI:

https://doi.org/10.1016/j.jclepro.2016.09.190

OLIVEIRA, J. L.; ALBUQUERQUE, A. L.; PEREIRA, R. D. Governança, sucessão e profissionalização em uma empresa familiar: (re)arranjando o lugar da família multigeracional. Revista Brasileira de Gestão de Negócios, v. 14, n. 43, p. 176-192, 2012. DOI: http://dx.doi.org/10.7819/rbgn.v14i43.881

OPLER, T. C.; TITMAN, S. Financial distress and corporate performance. The Journal of Finance, v. 49, n. 3, p. 1015-1040, 1994. DOI: https://doi.org/10.1111/j.1540-6261.1994.tb00086.x 
ORO, I. M.; BEUREN, I. M.; HEIN, N. Análise da eficiência de empresas familiares brasileiras. Revista de Administração de Empresas, v. 8, n. 2, p. 1-28, 2009. DOI: https://doi.org/10.1590/S167656482009000200006

PAMPLONA, E.; SILVA, T. P. da; NAKAMURA, W. T.; RODRIGUES JUNIOR, M. M. Influência da folga financeira no desempenho econômico de empresas familiares e não familiares brasileiras. Revista Contabilidade Vista \& Revista, v. 30, n. 1, p. 43-67, 2019. DOI: https://doi.org/10.22561/cvr.v30i1.4590

PINDADO, J.; RODRIGUES, L.; TORRE, C. de la. Estimating financial distress likelihood. Journal of Business Research, v. 61, n. 9, p. 995-1003, 2008. DOI: https://doi.org/10.1016/j.jbusres.2007.10.006

PLATT, H. D.; PLATT, M. B. Predicting corporate financial distress: Reflections on choice-based sample bias. Journal of Economics and Finance, v. 26, n. 2, p. 184-199, 2002. DOI:

https://doi.org/10.1007/BF02755985

RECHDEN, Claudio N.; MILLER, Kalina B. Company in distress? Directors needn't be-mitigating risks at the Board. The World Bank, 2015. Disponível em:

$<$ http://documents.worldbank.org/curated/en/167701468328788969/Company-in-distress-Directors-needntbe-mitigating-risks-at-the-Board>. Acesso em: 14 jul. 2018.

REZENDE, F. F.; MONTEZANO, R. M. da S.; OLIVEIRA, F. N. de; LAMEIRA, V. de J. Predicting financial distress in publicly-traded companies. Revista de Contabilidade \& Finanças, v. 28, n. 75, p. 490-406, 2017. DOI: http://dx.doi.org/10.1590/1808-057x201704460

RITTA, C. de O.; GORLA, M. C.; HEIN, N. Modelo de regressão logística para análise de risco de crédito em uma instituição de microcrédito produtivo orientado. Iberoamerican Journal of Industrial Engineering, v. 7, n. 13, p. 103-122, 2015.

SABELA, S. W.; BRUMMER, L. M.; HALL, J. H.; WOLMARANS, H. Using fundamental, market and macroeconomic variables to predict financial distress: A study of companies listed on the Johannesburg Stock Exchange. Journal of Economic and Financial Sciences, v. 11, n. 1, p. 1-11, 2018. DOI: https://doi.org/10.4102/jef.v11i1.168

SALEHI, M.; LOTFI, A.; FARHANGDOUST, S. The effect of financial distress costs on ownership structure and debt policy: An application of simultaneous equations in Iran. Journal of Management Development, v. 36, n. 10, p. 1216-1229, 2017. DOI: https://doi.org/10.1108/JMD-01-2017-0029

SANTOS, M. S.; MOREIRA, A. C.; VIEIRA, E. S. Ownership concentration, contestability, family firms, and capital structure. Journal of Management \& Governance, v. 18, n. 4, p. 1063-1107, 2014. DOI: https://doi.org/10.1007/s10997-013-9272-7

SCHMID, T. Control considerations, creditor monitoring, and the capital structure of family firms. Journal of Banking \& Finance, v. 37, n. 2, p. 257-272, 2013. DOI: https://doi.org/10.1016/j.jbankfin.2012.08.026

SMALL, R.; SMIDT, L.; JOSEPH, A. Financial distress - the responsibility of the professional accountant (SA): Accounting technical. Professional Accountant, v. 2016, n. 27, p. 20-21, 2016. Disponível em: https://journals.co.za/content/account/2016/27/EJC188562. Acesso em: 16 jul. 2018.

SUDARSANAM, S.; LAI, J. Corporate financial distress and turnaround strategies: An empirical analysis. British Journal of Management, v. 12, n. 3, p. 183-199, 2001. DOI: https://doi.org/10.1111/14678551.00193

VÃTAVU, S. The Impact of capital structure on financial performance in Romanian Listed Companies. Procedia Economics and Finance, v. 32, n. 1, p. 1314-1322, 2015. DOI: https://doi.org/10.1016/S22125671(15)01508-7

WHITAKER, R. B. The early stages of financial distress. Journal of Economics and Finance, v. 23, n. 2, p. 123-133, 1999. DOI: https://doi.org/10.1007/BF02745946

WRUCK, K. H. Financial distress, reorganization, and organizational efficiency. Journal of Financial Economics, v. 27, n. 1, p. 419-444, 1990. DOI: https://doi.org/10.1016/0304-405X(90)90063-6 


\section{NOTAS}

\section{AGRADECIMENTOS}

As contribuições recebidas no XVIII International Finance Conference (XVIII IFC) em 2018 e aos pareceristas anônimos da Revista Contemporânea de Contabilidade (RCC), que possibilitaram uma série de melhorias ao artigo.

\section{CONTRIBUIÇÃO DE AUTORIA}

Concepção e elaboração do manuscrito: E. Pamplona, A. C. Ames, T. P. da Silva

Coleta de dados: E. Pamplona, A. C. Ames

Análise de dados: E. Pamplona, A. C. Ames, T. P. da Silva

Discussão dos resultados: E. Pamplona, A. C. Ames, T. P. da Silva

Revisão e aprovação: E. Pamplona, A. C. Ames, T. P. da Silva

\section{CONJUNTO DE DADOS DE PESQUISA}

O conjunto de dados que dá suporte aos resultados deste estudo não está disponível publicamente.

\section{FINANCIAMENTO}

O presente trabalho foi realizado com apoio da Coordenação de Aperfeiçoamento de Pessoal de Nível Superior - Brasil (CAPES) - Código de Financiamento 001.

\section{CONSENTIMENTO DE USO DE IMAGEM}

Não se aplica.

\section{APROVAÇÃO DE COMITÊ DE ÉTICA EM PESQUISA \\ Não se aplica.}

\section{CONFLITO DE INTERESSES}

Não se aplica.

\section{LICENÇA DE USO}

Os Direitos Autorais para artigos publicados neste periódico são do autor, com direitos de primeira publicação para a Revista. Em virtude de aparecerem nesta Revista de acesso público, os artigos são de uso gratuito, com atribuições próprias, em aplicações educacionais, de exercício profissional e para gestão pública. A Revista adotou a licença Creative Commons Atribuição 4.0 Internacional - CC BY NC ND. Esta licença permite acessar, baixar (download), copiar, imprimir, compartilhar, reutilizar e distribuir os artigos desde que com a citação da fonte, atribuindo os devidos créditos de autoria. Nesses casos, nenhuma permissão é necessária por parte dos autores ou dos editores. Autores têm autorização para assumir contratos adicionais separadamente, para distribuição não-exclusiva da versão do trabalho publicada nesta revista (ex.: publicar em repositório institucional ou um capítulo de livro).

\section{PUBLISHER}

Universidade Federal de Santa Catarina. Curso de Ciências Contábeis e Programa de Pós-graduação em Contabilidade. Publicação no Portal de Periódicos UFSC. As ideias expressadas neste artigo são de responsabilidade de seus autores, não representando, necessariamente, a opinião dos editores ou da universidade.

\section{EDITORES}

Carlos Eduardo Facin Lavarda e Suliani Rover

\section{HISTÓRICO}

Recebido em: 14/01/2019 - Revisado por pares em: 11/05/2020 - Reformulado em: 14/06/2020 Recomendado para publicação em: 10/07/2020 - Publicado em: 30/07/2020

Uma versão preprint do artigo foi apresentada na XVIII International Finance Conference, 2018. 